\title{
Ecology and management of alien plant invasions in South African fynbos: Accommodating key complexities in objective decision making
}

\author{
Núria Roura-Pascual a,*, David M. Richardson ${ }^{\mathrm{a}}$, Rainer M. Krug ${ }^{\mathrm{a}, \mathrm{b}}$, Andrew Brown ${ }^{\mathrm{c}}$, R. Arthur Chapman ${ }^{\mathrm{d}}$, \\ Gregory G. Forsyth $^{\mathrm{d}}$, David C. Le Maitre ${ }^{\mathrm{d}}$, Mark P. Robertson ${ }^{\mathrm{e}}$, Louise Stafford ${ }^{\mathrm{f}}$, Brian W. Van Wilgen ${ }^{\mathrm{d}}$, \\ Andrew Wannenburgh ${ }^{\mathrm{g}}$, Nigel Wessels ${ }^{\mathrm{h}}$
}

a Centre for Invasion Biology, Department of Botany and Zoology, Stellenbosch University, Private Bag X1, Matieland 7602, South Africa

${ }^{\mathrm{b}}$ Plant Conservation Unit, Department of Botany, University of Cape Town, Private Bag X3, Rondebosch 7701, South Africa

${ }^{\mathrm{c}}$ Garden Route Initiative, South African National Parks, George, South Africa

${ }^{\mathrm{d}}$ Centre for Invasion Biology, CSIR Natural Resources and the Environment, P.O. Box 320, Stellenbosch 7599, South Africa

${ }^{\mathrm{e}}$ Centre for Invasion Biology, Department of Zoology and Entomology, University of Pretoria, Pretoria 0002, South Africa

${ }^{\mathrm{f}}$ Nature Conservation, City of Cape Town, Berkley Road, Maitland, 7405 Cape Town, South Africa

${ }^{\mathrm{g}}$ Department of Water Affairs and Forestry, Directorate: Working for Water, Private Bag X4390, Cape Town 8000, South Africa

${ }^{\mathrm{h}}$ Postnet Suite 200, Private Bag X6590, George 6530, South Africa

\section{A R T I C L E I N F O}

Article history:

Received 17 December 2008

Received in revised form 19 February 2009

Accepted 21 February 2009

Available online 9 April 2009

\section{Keywords:}

Analytic Hierarchy Process (AHP)

Biological invasions

Cape Floristic Region

DPSIR (Driving forces-Pressure-State-

Impacts-Responses) framework

Invasive alien plant species

Prioritization

\begin{abstract}
A B S T R A C T
Invasive alien trees and shrubs pose significant threats to biodiversity and ecosystem services in South African fynbos ecosystems. An ambitious initiative, the Working for Water program, commenced in 1995 to reduce the extent and impact of plant invasions. Despite substantial progress, the problem remains immense, and innovative ways of improving the efficiency of control operations are urgently needed. This study sought to develop a robust conceptual framework for effective management of the most important invasive alien plant (IAP) species. Two methods were applied in exploring the complexity of problems, thereby identifying appropriate response strategies. The DPSIR (Driving forces-PressureState-Impacts-Responses) framework and the Analytic Hierarchy Process (AHP) tool were used to design a strategy for prioritizing management actions. This strategy considers explicitly the most influential factors that determine the distribution, abundance, spread and impacts of IAPs. Efficient management of IAPs is constrained by multiple interacting environmental and socio-economic factors. Factors related to the fire-prone nature of the ecosystem and the characteristics of the invasive stands emerged as pivotal features for setting spatially-explicit priorities for management. Results of the analyses provide an objective and quantifiable perspective for improving the management efficiency. We conclude that considerable progress in controlling the spread of IAPs in fynbos ecosystems could be achieved by better coordination of management practices and by improving the quality of species distribution data.
\end{abstract}

(c) 2009 Elsevier Ltd. All rights reserved.

\section{Introduction}

Invasive alien species are a major threat to global biodiversity and ecosystem services (Mack et al., 2000). The need to respond effectively to biological invasions has promoted research which addresses the practical needs of conservation managers and policymakers. One of these needs is the development of decision-making tools to assist in setting priorities for management - to identifying

* Corresponding author. Tel.: +27 21808 2832; fax: +27 218082995.

E-mail addresses: nrourapascual@gmail.com (N. Roura-Pascual), rich@sun.ac.za (D.M. Richardson), Rainer@krugs.de (R.M. Krug), AndrewB@sanparks.org (A. Brown), achapman@csir.co.za (R.A. Chapman), gforsyth@csir.co.za (G.G. Forsyth), dlmaitre@csir.co.za (D.C. Le Maitre), mrobertson@zoology.up.ac.za (M.P. Robertson), Louise.Stafford@capetown.gov.za (L. Stafford), bvwilgen@csir.co.za (B.W. Van Wilgen), WannenA@dwaf.gov.za (A. Wannenburgh), nigelw@ssi.co.za (N. Wessels). the order in which species should be controlled, and to know when and where resources should be allocated to reduce the density and extent of invasive species. Research focused on guiding the management of invasive species is flourishing in the scientific literature. This work attempts to combine knowledge on the biology of invasive species with ecological process and management operations having an impact on them to provide standard mandates (Higgins et al., 2000; Hansen, 2007).

An example of the advances attained in controlling biological invasions is found in South Africa. Numerous plant species have been introduced over the past centuries, and many have invaded large areas of natural vegetation and are still spreading (Henderson, 2007). Some species transform ecosystems, affecting their capacity to provide services such as water production from catchments, soil maintenance, and nutrient cycling (Richardson and van Wilgen, 2004). With the implementation of the Working for Water 
program (WfW) in 1995, large-scale management interventions and applied research on IAPs were set in place (Richardson and van Wilgen, 2004). WfW aims to reduce the impacts of IAPs, while simultaneously creating employment opportunities in rural areas. It provides government, parastatal and NGO partners with resources to undertake the clearing of IAPs, mainly trees and shrub species.

Despite important advances, a major obstacle faced by project managers is the complex interactions among factors that influence the dynamics of the invasive species, and the interplay with a wide range of socio-political issues. This is especially complex and challenging in the fire-prone fynbos vegetation of the Cape Floristic Region (CFR) in the southwestern part of South Africa. The CFR is subjected to many external pressures (e.g. urbanization, human activities and climate change) that threaten the long-term persistence of its biological diversity. The remaining natural habitats are also under threat by the expansion of woody IAPs (Latimer et al., 2004). Despite the large investment of resources, it is unclear whether the extensive control operations are substantially reducing the dimensions of the problem and alleviating the threats to the region's biodiversity.

The aim of this study is to combine research on management of major woody IAPs (mainly species in the genera Acacia, Hakea and Pinus) in the CFR with insights derived from structured engagements with managers and other affected parties to develop a conceptual framework for improving the efficiency of control operations at a scale relevant to management actions (i.e. an extent of several hundred hectares). The two main objectives are:

(1) To make sense of the complexities involved in the spread of IAPs and the linkages between obstacles that hinder the efficiency of management strategies, to gauge insights into the most appropriate actions to improve current management practices.

(2) To identify and quantify the importance of key factors influencing the selection of priority areas for the management of IAPs to propose a standardized prioritization scheme for management at local scales.

Using the CFR as a case study, this study also sought new insights into the development of integrated strategies for managing IAPs across geographic regions and spatial scales. The role of both researchers and conservation managers in addressing these conservation issues and the importance of both working together will also be emphasized.

\section{Methods}

To address the above-mentioned objectives, we adopted two different methodological approaches - named Driver-PressureState-Impacts-Response (DSPIR) and Analytic Hierarchy Process (AHP), respectively - to synthesize information derived from experimental research and management experiences on the ground. To capture the full range of experiences and knowledge, the methodologies were applied at several workshops with experts on management of woody IAPs. Since several institutions (conservation agencies, private landowners, parastatal organizations) are currently responsible for managing IAPs in the CFR, workshops were run with groups comprising the widest possible cross-section of participants as possible (from theoreticians and academics to field managers) and with a wide institutional representation. Workshops were run by one facilitator (N. Roura-Pascual), who introduced and applied the methodologies described below. Participants were encouraged to delve into the processes involved in their decision making, but also to explore novel permutations and eventualities with the group. The facilitator summarized the information and produced outputs from each workshop. Four workshops were conducted, followed by several personal interviews to elucidate key issues.

\subsection{Understanding the spread of invasive alien plant species}

To contextualize the spread of woody IAPs at local scales in the CFR (Fig. 1), we identified the major driving forces, the linkages between these driving forces, and the stock of natural resources and the human activities utilizing them, or impacting on them, by using the DPSIR framework. The DPSIR, first presented in its current form by the European Environmental Agency (1995), is a useful analytical framework for describing interactions between society and the environment. It facilitates the understanding of complex systems by elucidating the relationships between large-scale socio-economic trends exerting pressures on the environment, the condition of the environment, and the response of the society to such conditions. The DPSIR framework has become widely used for structuring decision making in natural resource management (Bowen and Riley, 2003; Borja et al., 2006). It has also been used in analysing factors that facilitate the spread of invasive species (Elliott, 2003). We propose here to use the DPSIR for providing insights into the development of an integrated management for plant invasions in the CFR.

The framework is conceptualized as a chain of causal links composed of five components. Human activities in any economic or other sector (drivers) exert a pressure on the environment as a result of production or consumption processes. As a consequence of these socio-economic driving forces and augmented by the variability of natural systems, the state of the environment (i.e. the observable physical, chemical and biological conditions) changes; this may have environmental and economic impacts on ecosystems, biodiversity, human health and on the economic and social performance of society. These impacts, in turn, may elicit societal responses to any of the above components to mitigate or resolve the problems (Svarstad et al., 2008). Following Mangi et al. (2007) we also included a sixth component called barriers to effective management to explicitly highlight those limitations constraining the efficiency of the responses addressed to solve the problem. The description of this causal chain is complex; it starts by collecting information on the different components, and then identifying possible connections among them.

The DPSIR framework for the spread of woody IAPs at local scales in the CFR was discussed in a workshop with researchers working on IAPs (Stellenbosch, 3 October 2007). The aim of the analysis was to identify all elements that might play a role at a scale relevant for management in a theoretical region within the CFR, to provide a baseline in which to conduct similar analysis for some specific regions. After a brainstorming process, participants in the workshop described each component of the DPSIR framework and identified the linkages among them. Subsequent meetings with conservation managers were held to identify the relative strengths of different drivers in three different regions within the CFR: the Cape Peninsula; the Agulhas Plain (including the De Hoop Nature Reserve); and the Outeniqua, Wilderness and Knysna areas (Fig. 1). These regions were selected for comparison because of their distinct sets of biophysical and socio-environmental conditions, which influence the opportunities for management and therefore the state of biological invasions. While woody IAPs on the Cape Peninsula are relatively under control, problems in the other regions are immense, and the extent and density of invasive populations of most species is increasing. 

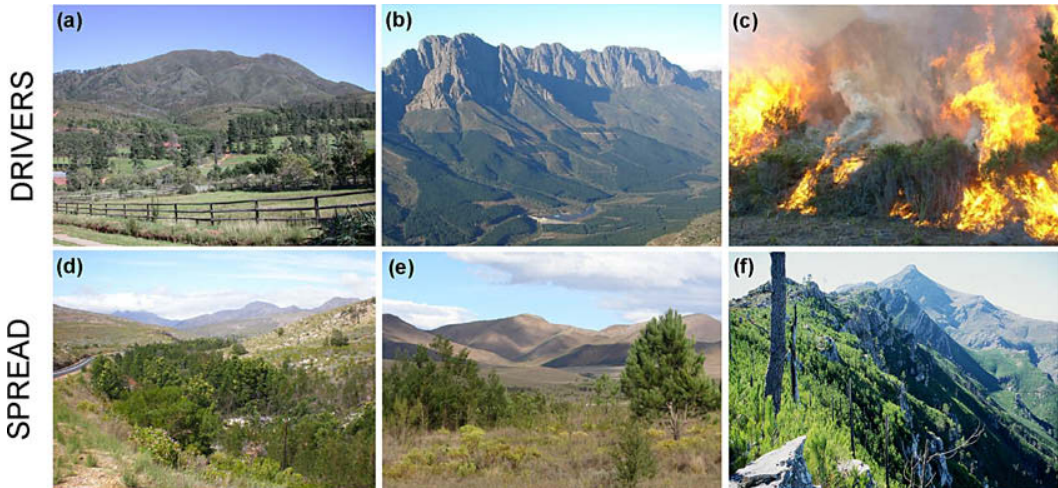

(e)
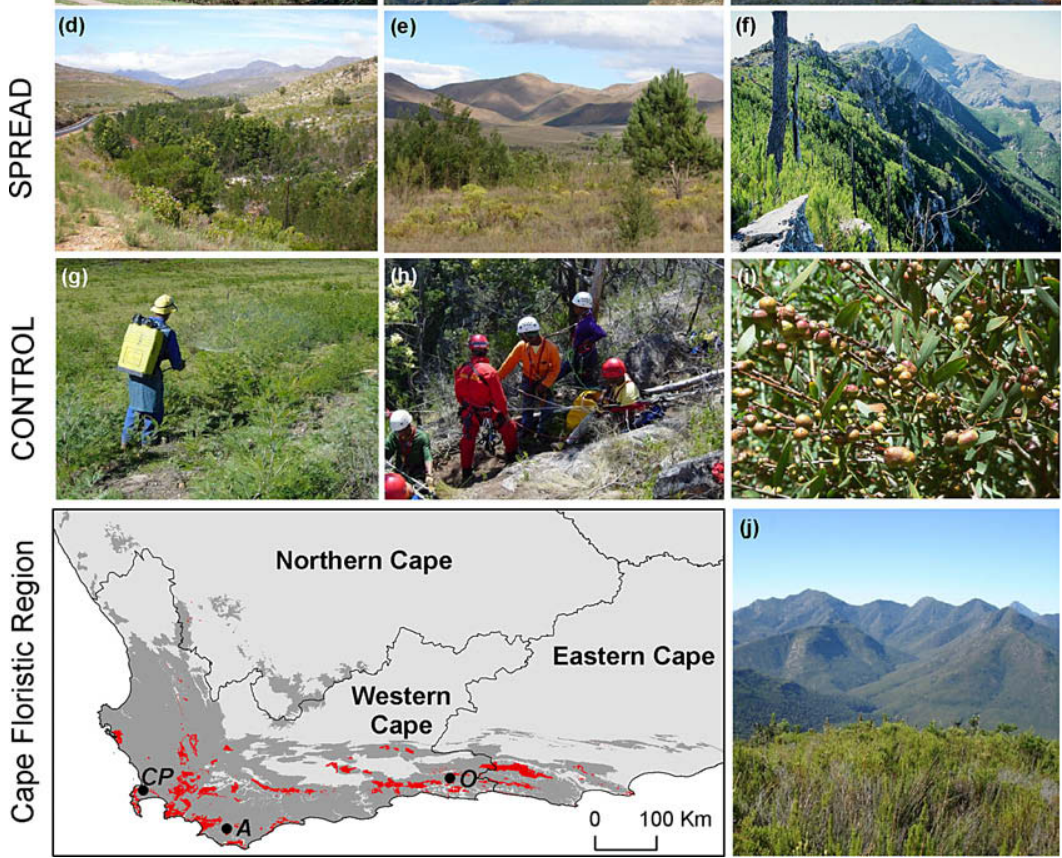

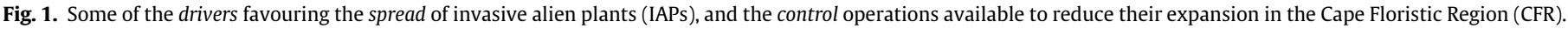

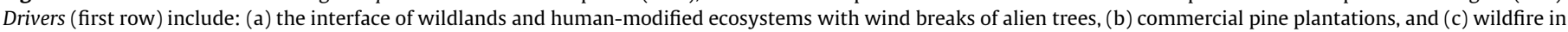

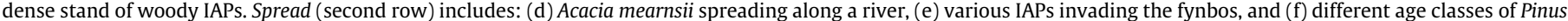

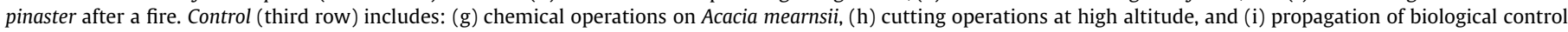

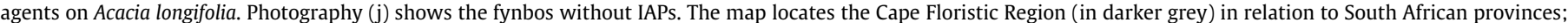

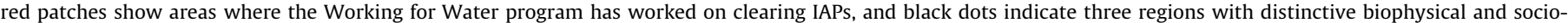

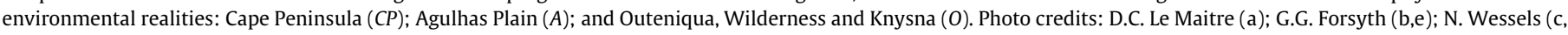
g, h); N. Roura-Pascual (d); D.M. Richardson (f, i); I. Paul (j).

\subsection{Prioritizing the management of invasive alien plant species}

Following elucidation of the context in which biological invasions occur, we developed a comprehensive and rational framework for prioritizing areas for managing woody IAPs at scales relevant to managers. The AHP methodology was used to synthesize information derived from experienced managers and researchers, and provides an objective way of ranking the factors involved in the selection of priority areas for management. A strength of AHP is its use of pair-wise comparisons of criteria to derive accurate ratio-scale priorities, as opposed to the traditional approach of assigning single weights (Saaty, 1980). AHP has been widely used in the scientific literature for numerous and distinct purposes (Vaidya and Kumar, 2006). It has specifically been applied in conservation management for identifying priority areas (Moffett et al., 2006; Valente and Vettorazzi, 2008), and integrated in risk assessments analysis for identifying species or areas at risk (Ou et al., 2008; van Wilgen et al., 2008). Here, we used the AHP to explore how agencies responsible for managing IAPs operate, the parameters and criteria that are applied in real-world decision making, and how these different elements interact to achieve a group consensus strategy for prioritizing areas for the IAPs management at local scales.

We used the understanding derived from the DPSIR analysis as a background for identifying the factors influencing management decisions, and grouped them into four categories according to their different nature: stand attributes, species attributes, socio-environmental context, and management context. Factors included in the first three categories were then ranked within each category according to their influence in deciding areas for clearing using a rational and quantifiable procedure. Factors included within the management context category were not ranked, because they are not under the control of the management agencies and they should not affect the final prioritization of clearing areas. However, we list them and discuss their importance.

We applied AHP using the Expert Choice decision support software v. 11.5.884 (๔ Expert Choice, Inc). This selection process involves setting a goal, breaking it down into its constituent parts, and then assigning relative weights to each of these. Scoring is on a relative basis comparing one choice with another (for example, "is knowing the density of the invaded stands - i.e. patches of invaded stands with homogeneous characteristics - more important than knowing the position of the patch in the landscape when prioritizing areas for clearing?"). Relative scores for each choice are computed for each level of the hierarchy. Scores are then synthesized through a model in Expert Choice that yields a composite score for each choice at every level and an overall score. The process is used to determine the relative importance of factors in relation to a specific goal thereby allocating more importance to a particular factor and its subsequent sub-factors (Saaty, 1980). The selection and ranking of the factors influencing management decisions was done at three different workshops (Jonkershoek, 11 
October 2007; Stellenbosch, 11 November 2007; Stellenbosch, 26 February 2008). As participants decomposed the problem at hand and built the conceptual framework for the prioritization scheme, they increased their understanding of the problem and of each other's experiences in managing IAPs. At the end of the process, participants were fully aware of how and why the decision was made and the results could be easily comprehended and communicated.

Upon completion of this process we converted the prioritization scheme into a map indicating prioritized areas for clearing within a GIS interface by taking into account the weight of the different factors included in the stand-attributes category. The region object of analysis was divided into cells of equal resolution $(100 \mathrm{~m} \times 100 \mathrm{~m})$ and each cell was characterized by seven attributes, one for each factor included in the stand-attributes category. Cell attributes were extracted from various digital coverage (time since the last fire, distribution and density of alien species, topography, history of the clearing operations, etc.) available for the region. A priority value was then assigned to each cell based on the properties of each cell and the weights assigned to the different factors included in the stand-attributes category. This resulted in a priority map for the selected region, which is the spatial representation of the consensus prioritization scheme and constitutes the end product in which managers can based their control strategies. The analysis was done using GRASS GIS software v. 6.2.3 ( GRASS Development Team), and it is explained in detail in the Supplementary methods in the electronic Supplementary material.

The species-attributes category was incorporated within the stand-attributes category through a factor called "Identity of IAPs", which corresponded to a priority list of the species that should be cleared first. Contrary to the stand attributes, the species prioritization was done within the Expert Choice software, which allowed us to make pair-wise comparisons among the elements to prioritize (i.e. major woody IAPs in the genera Acacia, Hakea and Pinus) while taking into account the weights assigned to each covering factor included in the species-attributes category. Species that were assessed as having high priority with regard to the higher ranking criteria were considered for alien clearing first. The process was done using the synthesis ideal mode, which control for changes in rank orders among the existing alternatives objected of the prioritization process (Forman and Gass, 2001). As the aim of the exercise is to prioritize areas to achieve sustainable management of IAPs, we considered it more appropriate to rank the species by including factors reflecting their invasive potential, rather than using prioritizations from various previous analyses that have classified IAPs in South Africa (Robertson et al., 2003; Nel et al., 2004). The category named socio-environmental context only plays a role in selecting areas for clearing when management operations are designed to enhance the biodiversity or economic activities of the area.

\section{Results}

\subsection{Understanding the spread of invasive alien plant species}

The DPSIR framework generated a conceptual model for understanding plant invasions in the CFR, and allowed us to: (1) clarify the linkages between the elements promoting the spread of IAPs; (2) identify the barriers hindering effective management; and (3) understand that regions with different biophysical and socio-environmental conditions have different particularities that need to be taken into consideration. Here, we describe the main results of the analysis with reference to the DPSIR framework.

The main drivers promoting the establishment and spread of IAPs in the CFR are both natural and socio-economic (Fig. 2). Natural drivers include the climatic conditions and disturbance

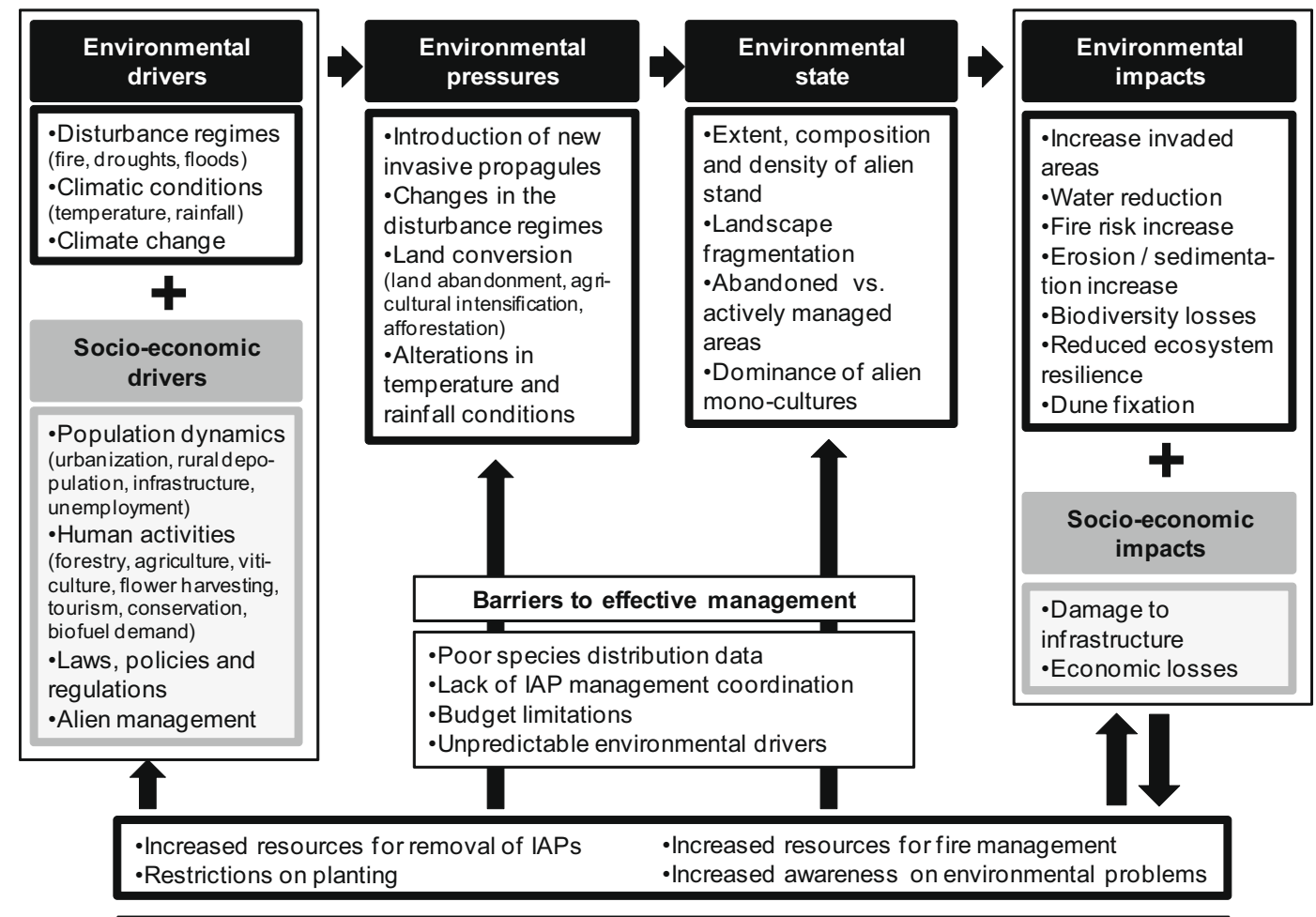

Responses

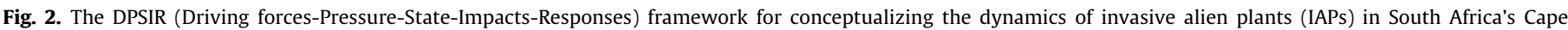

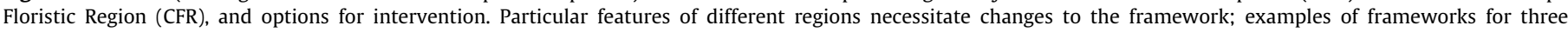
representative regions (Box 1) are presented in Fig. S1 in the electronic Supplementary material. 
regimes, while socio-economic forces emerge directly from human activities. The economic growth and increase in human population of the region have stimulated the depopulation of rural areas and induced changes in anthropogenic activities. While less-productive lands have been abandoned, more-productive areas have intensified their production. The growing awareness of the high natural diversity of the region has both promoted its conservation and attracted increasing numbers of tourists. These developments encouraged the adoption of various regulations and the WfW program for clearing woody alien plants.

Human activities enhance the economy of the region, but at the same time exert pressures on the environment by creating increased opportunities for the dissemination of propagules of IAPs and for the introduction of new potential invaders. The spread of IAPs is also favoured by altered disturbance regimes (such as fire or flooding), and augmented by long-term system variability (mainly due to climate). The result is that the state of the environment changes: the spread of woody IAPs transforms the landscape, which is already fragmented by actively managed areas, into dense monocultures of IAPs.

These alterations of the environmental state cause several impacts. For example, the presence of woody IAPs along watercourses and in watersheds increases transpiration losses and reduces the availability of water, and alters the natural sediment fluxes, increasing loss of top soils, erosion of stream banks, and sedimentation of stream beds (Le Maitre et al., 1996). Dense stands of woody IAPs also modify the disturbance regimes and reduce biodiversity, making the ecosystem less suitable for flower harvesting and more vulnerable to events such as droughts and floods (Higgins et al., 1997).

Several actions (responses) have already been initiated to reduce the negative impacts associated with IAPs. The most notable is the substantial resources invested by WfW in managing IAPs and fire, both to reduce the extent of invasions and to ensure the sustained delivery of water and the conservation of biodiversity. A range of other responses are evident, including attempts to improve legislation to facilitate improved management of IAPs, and the establishment of partnerships between national and regional nursery organizations and authorities responsible for managing invasive species to reduce the dissemination of invasive ornamental plant species (Richardson et al., 2004). However, the capacity of these measures to control IAPs is limited by several other elements.

The main barriers to effective management are linked to the management context within which management operations operate. Although management of IAPs is a priority for all partner agencies, many problems are experienced with the complex logistics involved in the decision-making process. The location and size of areas to be cleared and the scheduling of initial and follow-up operations has a dramatic impact on total area cleared due to variability in the spread and density of the IAPs. Nevertheless, there is an important lack of occurrence and distribution data of IAPs across landscapes and an absence of clear mandates on how to operate in a coordinated manner. The spatial complexity of the environment, and the many variables that influence outcomes at a regional level, preclude the use of simple rule-based decision systems to optimize the investment of limited resources.

Additionally, comparisons between DPSIR frameworks for three representative regions in the CFR (Fig. S1 in the electronic Supplementary material) revealed that differences in habitat fragmentation, accessibility of the region and organizational constraints (i.e. lack of a unique and clear mandate to carry out control operations, and budgetary limitations) result in clear differences in approaches and strategies for managing IAPs (Box 1). Different geographic regions have their own environmental and management complexities that demand special attention when seeking reasons for the proliferation of IAPs and when exploring complexities associated with management.

Box 1. Differences between three selected areas in the Cape Floristic Region that influence options for managing invasive alien plants.

Because the influence of major driving forces and impacts caused by biological invasions differs markedly within the CFR, we repeated the DPSIR (Driving forces-Pressure-State-Impacts-Responses) framework for three different regions, each with a distinctive set of biophysical and socio-environmental conditions: the Cape Peninsula; the Agulhas Plain (including the De Hoop Nature Reserve); and the Outeniqua, Wilderness and Knysna areas (Fig. 1).

The DPSIR frameworks (Fig. S1 in the electronic Supplementary material) indicate that invasive alien plants (IAPs) are a major problem in all three regions, but different environmental and socio-economic contexts influence options for management. The entire Cape Peninsula is affected by rapid urbanization, but most of the remaining natural area is protected in a national park. The budget and human resources available to combat IAPs is greater per unit area than for other parts of the CFR, leading to substantial and well-managed control efforts. The very long boundary between urban/suburban land and natural areas does, however, provide many opportunities for incursions of IAPs and also complicates management operations (Richardson et al., 1996; Alston and Richardson, 2006).

On the Agulhas Plain the budget for clearing IAPs is relatively small, and operations on public and private land have been poorly coordinated and relatively ineffective in reducing density and containing spread of IAPs. This region has a complex mixture of private and public landownership with multiple land uses, resulting in highly fragmented mosaic with actively managed areas interspersed with unmanaged land. The main barrier to successful management of invasive species in the region is the lack of a single strategic management plan.

The situation in Outeniqua, Wilderness and Knysna areas is very different from the other two regions. Although most invaded patches within the limits of the Outeniqua Nature Reserve have been cleared, unmanaged dense stands of IAPs occur along the eastern edge of the region, mainly in inaccessible terrain. The main constraint on managing existing IAP problems and curbing future spread is the mountainous topography. These source areas, together with additional sources areas created by extensive commercial pine plantations, facilitate the spread of IAPs onto currently uninvaded areas within the region.

Even though there is a common background, each region has its own management constraints that must be considered when formulating efficient management decisions.

\subsection{Prioritizing the management of invasive alien plant species}

We identified 28 main factors, which in turn were subdivided into a smaller number of sub-factors, and ranked using the AHP (Table 1). The most important factor influencing the selection of invaded areas for management within a specific region is the opportunity that follows after a fire to remove IAPs before they mature (Table 1A). Secondly, priority is given to parts of the landscape with low-density coverage of IAPs ( $<25 \%$ cover) - to prevent densification associated with fires - and to areas where the potential for 
Table 1

Factors and sub-factors influencing the management of invasive alien plants (IAPs) at local scales in the Cape Floristic Region grouped into four categories: stand attributes (A), species attributes (B), environmental context (C), and management context (D). Values associated with each factor indicate its importance $(0-1)$ within the category and all values sum up to 1 . Values for each sub-factors (0-1) indicate its relative importance within that specific factor and sum up to 1 . For example, the factor relating to the effectiveness of available biological control agents has an importance of 0.38 compared to the rest of the factors within the species-attributes category, and the sub-factor "no/negligible control" an importance of 0.73 within this factor. Based on these scores, invasive species with no current biological control options will be prioritized for attention over those for which effective biological control is available. The management context factors were not scored because they are not under the control of the agencies responsible for control operations and, thus, cannot be considered for prioritizing areas within a specific region at this scale of analysis. See Table S1 in the electronic Supplementary material for a description of the factors and sub-factors presented in the table.

\begin{tabular}{|c|c|c|}
\hline \multicolumn{3}{|l|}{ (A) Stand attributes } \\
\hline Area burnt recently? & & 0.40 \\
\hline Yes & 0.90 & \\
\hline No & 0.10 & \\
\hline Density of IAPs? & & 0.17 \\
\hline Close ( $>75 \%$ cover $)$ & 0.03 & \\
\hline Dense (50-75\%) & 0.04 & \\
\hline Medium (25-50\%) & 0.06 & \\
\hline Scattered (5-25\%) & 0.10 & \\
\hline Very scattered (1-5\%) & 0.20 & \\
\hline Occasional $(<1 \%)$ & 0.38 & \\
\hline Rare (some individuals) & 0.19 & \\
\hline Spread based on topography? & & 0.17 \\
\hline Low & 0.07 & \\
\hline Medium & 0.30 & \\
\hline High & 0.65 & \\
\hline Area at fire risk? & & 0.13 \\
\hline Low & 0.07 & \\
\hline Medium & 0.30 & \\
\hline High & 0.65 & \\
\hline Age of IAPs? & & 0.06 \\
\hline Adult & 0.10 & \\
\hline Sapling & 0.64 & \\
\hline Seedling & 0.26 & \\
\hline Identity of IAPs? & & 0.05 \\
\hline Last clearing operation? & & 0.03 \\
\hline No treatment & 0.05 & \\
\hline Initial & 0.30 & \\
\hline Follow-up & 0.55 & \\
\hline Maintenance & 0.10 & \\
\hline \multicolumn{3}{|l|}{ (B) Species attributes } \\
\hline Biological control effective? & & 0.38 \\
\hline No/negligible control & 0.73 & \\
\hline Limited control & 0.21 & \\
\hline Substantial control & 0.06 & \\
\hline Importance of fire for spread? & & 0.30 \\
\hline Yes & 0.90 & \\
\hline No & 0.10 & \\
\hline Generalist habitat requirements? & & 0.10 \\
\hline Generalist & 0.86 & \\
\hline Specialist & 0.14 & \\
\hline Long-distance dispersal? & & 0.10 \\
\hline Water & 0.27 & \\
\hline Wind & 0.55 & \\
\hline Birds & 0.13 & \\
\hline In situ & 0.05 & \\
\hline Fast maturing? & & 0.05 \\
\hline Fast (<3 years) & 0.88 & \\
\hline Slow (>3 years) & 0.12 & \\
\hline Sprouting ability? & & 0.04 \\
\hline Sprouter & 0.88 & \\
\hline Non-sprouter & 0.12 & \\
\hline Long-term storage of seeds? & & 0.03 \\
\hline Long lived seeds in soil & 0.65 & \\
\hline Short lived seeds in soil & 0.07 & \\
\hline Serotinous & 0.28 & \\
\hline
\end{tabular}

Table 1 (continued)

\begin{tabular}{|c|c|c|}
\hline (C) Environmental context & & \\
\hline $\begin{array}{l}\text { High conservation value? } \\
\text { Critically endangered } \\
\text { Endangered } \\
\text { Vulnerable } \\
\text { Least vulnerable }\end{array}$ & $\begin{array}{l}0.57 \\
0.30 \\
0.09 \\
0.05\end{array}$ & 0.36 \\
\hline $\begin{array}{l}\text { Neighbouring areas at fire risk? } \\
\text { High } \\
\text { Low }\end{array}$ & $\begin{array}{l}0.83 \\
0.17\end{array}$ & 0.26 \\
\hline $\begin{array}{l}\text { Endangered species present? } \\
\text { Yes } \\
\text { No }\end{array}$ & $\begin{array}{l}0.09 \\
0.10\end{array}$ & 0.16 \\
\hline $\begin{array}{l}\text { Invasion from neighbouring areas? } \\
\text { High } \\
\text { Low }\end{array}$ & $\begin{array}{l}0.87 \\
0.13\end{array}$ & 0.11 \\
\hline Sustainable economic activities? & & 0.08 \\
\hline $\begin{array}{l}\text { Potential for restoration? } \\
\text { Low } \\
\text { Medium } \\
\text { High }\end{array}$ & $\begin{array}{l}0.06 \\
0.21 \\
0.73\end{array}$ & 0.03 \\
\hline (D) Management context & & \\
\hline $\begin{array}{l}\text { Sufficient funds available? } \\
\text { Planning scale? } \\
\text { Management capacity? } \\
\text { Institutional capacity? } \\
\text { Political motivations? } \\
\text { Quality of species distribution data? } \\
\text { Any legislation/funder prescriptions? } \\
\text { Landownership of the area to clear? }\end{array}$ & & \\
\hline
\end{tabular}

spread into neighbouring areas is high. Potential for spread is determined by the position of the IAPs in the landscape, e.g. wind-dispersed species on upper slopes and water-dispersed species in upper catchments. Additionally, areas with a high probability of fire (i.e. high fire risk based on stand age, position in the landscape, and fire frequency) are also prioritized for clearing (Table $1 \mathrm{~A}$ ). Contrary to initial expectations, the identity of the species present in a stand is relatively unimportant (and received a low score) when prioritizing the stands for clearing (Table 1A).

The availability of an effective biological control agent and the importance of fire in stimulating population growth of the species were the most important factors for deciding which species to target first (Table 1B). Based on the importance of factors and sub-factors included within this category, species having the highest priority for clearing (ranking from 0 to 1 , totaling 1 ) are Pinus halepensis (relative priority of 0.14), Pinus pinaster (0.14), Pinus radiata (1.3), Acacia mearnsii (0.09) and Acacia melanoxylon (0.09). This can be attributed to the absence (for pines) or inefficiency of biological control agents, and the importance of fire in stimulating their population growth. If the efficacy of biological control agents is not considered, the following species ranked as most important (based on their intrinsic characteristics): Acacia mearnsii (0.12), Acacia longifolia (0.12), Acacia saligna (0.11), Pinus halepensis (0.11), Hakea sericea (0.11) and Pinus pinaster (0.11) (Fig. S2 in the electronic Supplementary material). Overall, it is important to note that species-based prioritization has little influence in the final prioritization scheme because its weight is only $0.05(5 \%)$ of the total score (Table 1A).

Factors grouped as stand attributes are the most important for deciding which areas to manage first within a selected region. However, when a region needs to be prioritized for conservation purposes, factors grouped within the environmental context category may be important to consider. These factors include the status of the area for conservation purposes (e.g. protected areas are generally given priority) or for sustainable economic activities, the 
conservation value (based on the vegetation type of the area), and the risk of fire spreading from neighbouring areas (Table 1C). It must be noted that we did not include any factors relating to water resources in this category. Although potential for water production from catchments is a primary factor in planning at larger spatial scales (Dye and Poulter, 1995; Prinsloo and Scott, 1999), when selecting regions within the CFR to prioritize, this factor was not considered appropriate for planning at the local scale.

Finally, although they were not included in the spatial prioritization scheme, several factors related to the management context also influence (both positively and negatively) the day-to-day planning of control operations (Table 1D). These eight management-related factors identified during our workshop correspond to economic (available budget), organizational (data quality, planning scales, management and institutional capacity, and landownership), and regulatory constraints (legislation and political issues). While budget availability is essential for conducting clearing operations, regulatory prescriptions and organizational capacity are ultimately responsible for achieving satisfactory results, i.e. reducing the extent and density of IAPs.

\section{Discussion}

The overall DPSIR framework enabled us to simplify the understanding of the spread of the IAPs in the CFR, and make sense of the limitations of the current management strategy and the singularities among regions within the CFR. Obstacles to achieving improved management relate to the inherent complexity of the interactions that determine the distribution and abundance of IAPs, and to a range of practical issues affecting the logistics of the management operations in the face of multiple factors. Some of these are related to the environment in which the intervention is required, whereas others are linked to the management practice itself.

Although legal instruments and the WfW program for clearing IAPs are in place, many ongoing human activities promote further introduction, dissemination, and invasion. Forestry activities and horticulture are among the primary forces that drive introductions and dissemination of IAPs in the CFR (Rouget et al., 2003; Le Maitre et al., 2004). Climatic conditions and disturbance regimes (mainly fires, but also floods), including changes in their variability, also create opportunities for the successful establishment of IAPs (Midgley et al., 2005). Differences in biophysical and management characteristics among regions within the CFR produce different sets of complexities, which need to be addressed individually and in an integrated way for conducting appropriate management actions. Despite actions set in place to curb expansion, the area occupied by IAPs is increasing, exacerbating environmental and socio-economic impacts (Latimer et al., 2004). Elements hindering effective management include funding insecurity, the shortage of adequate management capacity (uncertain mandates and uncoordinated management), and weak operational management and monitoring (especially due to the lack of detailed and up-to-date data on the distribution of IAPs). Despite past research efforts to determine strategies for control operations in particular localities (e.g. Macdonald and Wissel, 1992), no objective framework is in place for identifying priorities, and for scheduling and monitoring of IAP control operations. Innovative ways of improving the efficiency of control operations are needed.

In an attempt to condense the many types of information that potentially play a role in decision making for managing IAPs in the CFR, we constructed a single conceptual model. The approach permitted us identify factors to take into consideration for IAP management and enabled us to derive a spatial prioritization of the areas for clearing within a selected region based on a consensus
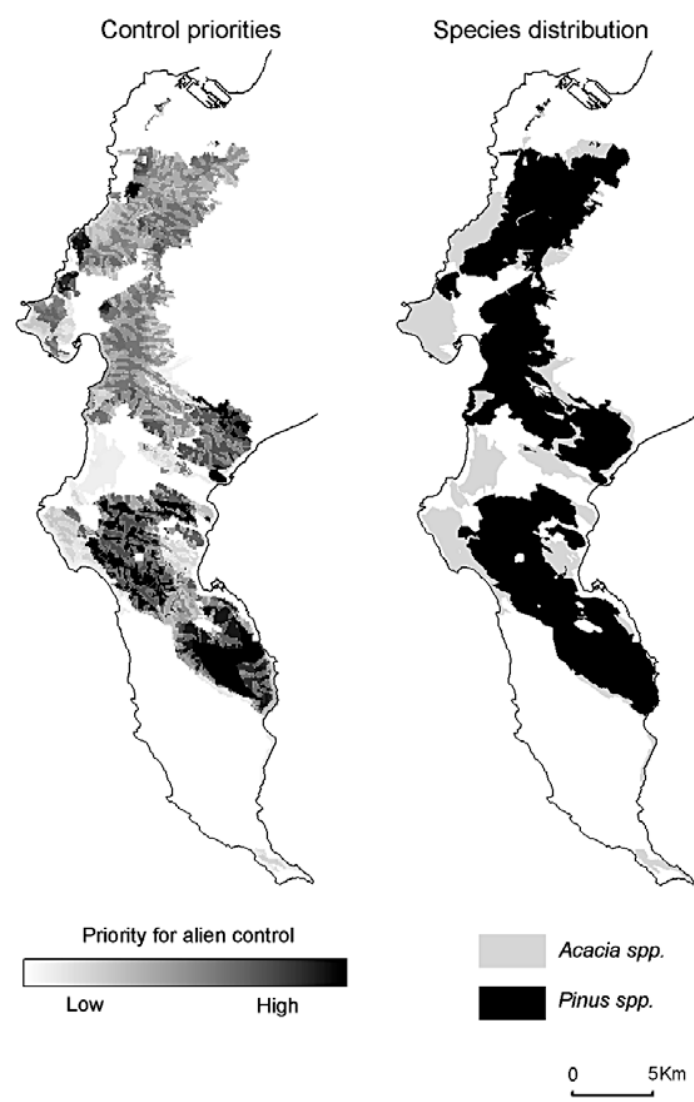

Fig. 3. Example of a spatial prioritization exercise for the Cape Peninsula region. The map on the left shows areas prioritized for management based on the characteristics of the invaded stands and the invasive alien plants (IAPs) (Table 1, A and $\mathrm{B}$ ). The map on the right shows the distribution of IAPs before the clearing operations. Comparing the two maps highlights the low importance of the identity of species present when prioritizing areas for management.

agreement between managers and researchers (see Fig. 3 for an example of a spatial representation of the derived prioritization). Although factors related to the environmental value of the area and the management context also play an important role in managing IAPs, they were not considered in the spatial prioritization. The environmental context was considered homogeneous at the fine spatial scale of our analysis, and operational issues influencing the management decisions were considered as constraints to the prioritization process derived from a limited budget or operational capacity. However, it is important to note that these factors need to be considered when prioritizing areas at broader scales and with more heterogeneous environments; for example, water catchments within the CFR or biomes within South Africa, as opposed to regions object of our analysis that have a smaller extent.

Overall, our approach identified factors related to the fire-prone nature of the ecosystem and the characteristics of the invaded stands as the most influential in setting spatial priorities for management of IAPs. Contrary to previous strategies for controlling IAPs (e.g. Wadsworth et al., 2000), the identity and spatial extent of the IAPs were not highlighted as important for management, and received low scores or were excluded from the outset. This may appear anomalous given the wide range of life-history traits among the main invasive species (e.g., pines with canopy-stored seeds and wind-dispersed seeds through to acacias with soilstored seeds dispersed in soil or water and by animals). The reason is that all of the main invasive trees and shrubs species in the fynbos are well adapted to flourish in the fire-prone, nutrient-poor environments, and spread rates are fairly similar for the different 
species (Richardson and Cowling, 1992). On the other hand, the strategy developed here is in agreement with results from other research in prioritizing control measures on the basis of the characteristics of invasive populations (i.e. stand density) (Higgins et al., 2000). Using the full spectrum of criteria that affect invasive spread and potentially influence management efficiency is important for moving beyond the prevailing situation in which prioritization is based on a subset of criteria, often conservation value and the availability and quality of data on IAP distribution and abundance (Hulme, 2003).

The identification of these most influential factors for managing IAPs is, however, not arbitrary and the final prioritization of the areas for clearing depends on the: (1) nature of the region (i.e. a fire-prone ecosystem), (2) characteristics of the IAPs under consideration (i.e. invasive trees and shrubs with high dispersal potential), and (3) scale of analysis (i.e. management units at landscape scales). Therefore, the transferability of this prioritization scheme to other geographic areas and operational contexts will largely depend on the characteristics of these previous elements. If the region under consideration matches the characteristics used to develop this prioritization scheme, then the various factors will operate in a similar fashion and the prioritization can be implemented with minor changes.

\subsection{Nature of the region}

The prioritization scheme presented in this study was developed for the Cape Floristic Region, a Mediterranean-type ecosystem where IAP species, mainly trees and shrubs, have invaded large areas. Several studies have recognized the crucial role of fire in shaping the distribution and abundance of both native and alien species in Mediterranean-type ecosystems (Kruger, 1983). This is reflected in our prioritization scheme, which highlighted two fire-related factors as being crucial for effective management of IAPs. Fires that kill the existing plants stimulate seed release from serotinous cones or follicles, stimulate germination of soil-stored seeds, and create suitable conditions for seedling growth (Richardson and Cowling, 1992). This provides a period during which control operations can kill the seedlings or saplings before they mature. The cost of treatment at this stage is typically relatively low because the plants are small. Once they have matured the opportunity for easy or cheap control is lost. Coordinating control operations with fire cycles is a major challenge for effective management. Wildfires promote rapid population growth and spread of invasive trees and shrubs in fynbos, but planned fires are a crucial part of integrated control measures for controlling invasions (van Wilgen et al., 1994). The strong link between fire and the spread of IAPs and opportunities for managing them is unique among the world's five regions with Mediterranean-type climate. Hence, although fire certainly influences IAPs in the other regions, we would expect a very different framework in these regions to that developed for the CFR. Other unique features of the CFR (e.g. vast extent of woody IAPs and a low level of anthropogenic disturbance over large areas) also mean that the prioritization scheme we developed will not be directly transferable. However, the approach we followed is transferable, and it would be interesting to apply these methods in other regions and compare the resulting weightings of factors.

\subsection{Characteristics of the invasive species to manage}

The prioritization framework was developed considering only the conditions pertaining to the ecology and management of the most highly invasive alien trees and shrubs in the CFR: species of Acacia, Hakea, and Pinus. These taxa have the capacity to spread into natural ecosystems without human intervention, and dominate large tracts of fynbos. Management of these major IAPs comprises the bulk of control efforts (Marais et al., 2004). Several other species also receive management attention, and others are increasing in importance (Henderson, 2007). Accommodating such species in overall management strategies is important, but the challenges relating to such species are different to those that form that basis of our analysis. For example, for emerging invaders priority is ideally given to eradication efforts where this is feasible and to implement biological control to limit spread where eradication is not practical (Olckers, 2004). Management of herbaceous species specifically requires different management approaches.

\subsection{Scale of management}

Since processes and environmental variables determining the distribution of species are scale dependent (Wiens, 1989), spatial scale plays a fundamental role in ranking the factors included in the prioritization scheme. The prioritization presented here was designed to assist with the management of landscape units (typically several hundred hectares in extent). Consequently, factors relevant and operating at other spatial scales (e.g., importance of the area as a watershed for regional water provision, conservation value of the area, adherence to national legislation, prioritization focused on job creation rather than ecological issues) (van Wilgen et al., 2007) were excluded from our exercise. Our prioritization should be applied in landscape selected by local-scale planning and therefore does not need to include larger scale factors.

\section{Conclusions}

The overall approach used to prioritize areas for management of IAPs within a selected region resulted in an intuitive framework for dealing with the complexities involved in decision-making processes. It also offered managers and scientists an opportunity to share experiences and knowledge on best-management practices for controlling IAPs in a quantifiable perspective, while simultaneously highlighting important constraints that hamper effectiveness of management operations. We suggest that considerable improvements in the management of IAPs in fynbos would be achieved by: (1) coordinating and synchronizing control operations at both regional and local scales; (2) establishing clear mandates on how to proceed with control operations; and (3) improving the quality of distribution data for IAPs. We suggest that the main contribution of the conceptual framework designed for prioritizing areas for clearing in this paper has been the creation of an informative scheme for guiding best-management practices. It provides managers with a set of rules derived from the combined experience of experts in the field, and facilitates transparent decision making. Despite the subjectivity of the source of information (experts' perspectives and experiences), the overall approach provided a robust framework for making use of available information on decision making.

The spatial prioritization of control operations is of vital importance for managing invasive species, but it is necessary to assess the effectiveness and consequences of these clearing strategies under different budgetary and temporal contexts. The development of a spatially-explicit spread model to simulate the effects of different clearing operations (both spatially and temporally) on plant invasions is in progress and will be helpful for improving the management of IAPs in the CFR (Higgins et al., 2000). The potential of such a decision-modeling approach in guiding the management of IAPs in a cost-efficient manner will, however, only be realized if appropriate data are available. Reliable maps of distribution of IAPs and the capacity to monitor IAPs at the appropriate spatial 
scale are essential requirements for effective and sustainable management of IAPs.

We encourage the use of similar approaches in other regions to provide guidelines for application across various vegetation-types and scales of management. Winning the conservation war against biological invasions will only be possible through the development of integrated management strategies and with the appropriate allocation of resources across spatial scales (Hulme, 2003). However, such decision-making tools can only support conservation initiatives if they can assist in identifying and addressing the most critical challenges and present results in the appropriate format for resource managers.

\section{Acknowledgements}

Thanks are due to many people who helped us to understand the informal decision framework underpinning invasive alien plant management in the CFR. R. Bailey, L. Bezuidenhout, G. Cleaver, N. Cole, D. Kirkwood, D. Malan, P. Marsh, R. Miles, G. Palmer, L. Potter, C. Steenkamp, and L. Waller were particularly helpful. The project was funded by the Global Environmental Facility (GEF) through the Cape Action for People and the Environment (CAPE) program. We also acknowledge financial support from the DST-NRF Centre of Excellence for Invasion Biology, the Catalan Agency for Management of University and Research Grants (Generalitat de Catalunya) through a Beatriu de Pinós Postdoctoral Grant (2006 BP-A 10124) to N. Roura-Pascual, and a grant from the Hans Sigrist Foundation to D.M. Richardson.

\section{Appendix A. Supplementary material}

Supplementary material associated with this article can be found, in the online version, at doi:10.1016/j.biocon.2009.02.029.

\section{References}

Alston, K.P., Richardson, D.M., 2006. The roles of habitat features, disturbance, and distance from putative source populations in structuring alien plant invasions at the urban/wildland interface on the Cape Peninsula, South Africa. Biological Conservation 132, 183-198.

Borja, A., Galparsoro, I., Solaun, O., Muxika, I., Tello, E.M., Uriarte, A., Valencia, V., 2006. The European Water Framework Directive and the DPSIR, a methodological approach to assess the risk of failing to achieve good ecological status. Estuarine Coastal and Shelf Science 66, 84-96.

Bowen, R.E., Riley, C., 2003. Socio-economic indicators and integrated coastal management. Ocean \& Coastal Management 46, 299-312.

Dye, P.J., Poulter, A.G., 1995. A field demonstration of the effect of streamflow of clearing invasive pine and wattle trees from a riparian zone. South African Forestry Journal 173, 27-30.

Elliott, M., 2003. Biological pollutants and biological pollution - an increasing cause for concern. Marine Pollution Bulletin 46, 275-280.

EEA, 1995. Europe's Environment: the Dobris Assessment. European Environmental Agency, Copenhagen.

Forman, E.H., Gass, S.I., 2001. The analytic hierarchy process - an exposition. Operations Research 49, 469-486.

Hansen, M.J., 2007. Evaluating management strategies and recovery of an invasive grass (Agropyron cristatum) using matrix population models. Biological Conservation 140, 91-99.

Henderson, L., 2007. Invasive, naturalized and casual alien plants in southern Africa: a summary based on the Southern African Plant Invaders Atlas (SAPIA). Bothalia 37, 215-248.

Higgins, S.I., Turpie, J.K., Costanza, R., Cowling, R.M., Le Maitre, D.C., Marais, C., Midgley, G.F., 1997. An ecological economic simulation model of mountain fynbos ecosystems - dynamics, valuation and management. Ecological Economics 22, 155-169.

Higgins, S.I., Richardson, D.M., Cowling, R.M., 2000. Using a dynamic landscape model for planning the management of alien plant invasions. Ecological Applications 10, 1833-1848.

Hulme, P.E., 2003. Biological invasions: winning the science battles but losing the conservation war? Oryx 37, 178-193.

Kruger, F.J., 1983. Plant community diversity and dynamics in relation to fire. In: Kruger, F.J., Mitchell, D.T., Jarvis, J.U.M. (Eds.), Mediterranean-type Ecosystems: The Role of Nutrients. Springer-Verlag, Berlin, pp. 446-472.
Latimer, A.M., Silander, J.A., Gelfand, A.E., Rebelo, A.G., Richardson, D.M., 2004. A method for quantifying the magnitude of threat to plant biodiversity from alien plant invasions and other anthropogenic factors - a case study in the Cape Floristic Region, South Africa. South African Journal of Science 100, 8186.

Le Maitre, D.C., van Wilgen, B.W., Chapman, R.A., McKelly, D.H., 1996. Invasive plants and water resources in the Western Cape Province, South Africa: modelling the consequences of a lack of management. Journal of Applied Ecology 33, 161-172.

Le Maitre, D.C., Richardson, D.M., Chapman, R.A., 2004. Alien plant invasions in South Africa: driving forces and the human dimension. South African Journal of Science 100, 103-112.

Macdonald, I.A.W., Wissel, C., 1992. Determining optimal clearing treatments for the alien invasive shrub Acacia saligna in the southwestern Cape, South-Africa. Agriculture Ecosystems \& Environment 39, 169-186.

Mack, M.C., Simberloff, D., Lonsdale, W.M., Evans, H., Clout, M., Bazzaz, F.A., 2000 Biotic invasions: causes, epidemiology, global consequences, and control. Ecological Applications 10, 689-710.

Mangi, S.C., Roberts, C.M., Rodwell, L.D., 2007. Reef fisheries management in Kenya: preliminary approach using the driver-pressure-state-impactsresponse (DPSIR) scheme of indicators. Ocean \& Coastal Management 50, 463-480.

Marais, C., van Wilgen, B.W., Stevens, D., 2004. The clearing of invasive alien plants in South Africa: a preliminary assessment of costs and progress. South African Journal of Science 100, 97-103.

Midgley, G.F., Chapman, R.A., Hewitson, B., Johnston, P., de Wit, M., Ziervogel, G., Mukheibir, P., van Niekerk, L., Tadross, M., van Wilgen, B.W., Kgope, B., Morant, P.D., Theron, A., Scholes, R.J., Forsyth, G.G., 2005. A status quo, vulnerability and adaptation assessment of the physical and socio-economic effects of climate change in the Western Cape. Report to the Western Cape Government, Cape Town, South Africa. CSIR, Stellenbosch.

Moffett, A., Dyer, J.S., Sarkar, S., 2006. Integrating biodiversity representation with multiple criteria in North-Central Namibia using non-dominated alternatives and a modified analytic hierarchy process. Biological Conservation 129, 181-191.

Nel, J.L., Richardson, D.M., Rouget, M., Mgidi, T.N., Mdzeke, N., Le Maitre, D.C., van Wilgen, B.W., Schonegevel, L., Henderson, L., Neser, S., 2004. A proposed classification of invasive alien plant species in South Africa: towards prioritizing species and areas for management action. South African Journal of Science 100, 53-64.

Olckers, T., 2004. Targeting emerging weeds for biological control in South Africa: the benefits of halting the spread of alien plants at an early stage of their invasion. South African Journal of Science 100, 64-68.

Ou, H., Lu, C.Y., O'Toole, D.K., 2008. A risk assessment system for alien plant bioinvasion in Xiamen, China. Journal of Environmental Sciences-China 20, 989997.

Prinsloo, F.W., Scott, D.F., 1999. Streamflow responses to the clearing of alien invasive trees from riparian zones at three sites in the Western Cape Province. Southern African Forestry Journal 185, 1-7.

Richardson, D.M., Cowling, R.M., 1992. Why is mountain fynbos invisible and which species invade? In: van Wilgen, B.W., Richardson, D.M., Kruger, F.J., van Hensbergen, H.J. (Eds.), Fire in South African Mountain Fynbos. Springer-Verlag, Berlin, pp. 161-181.

Richardson, D.M., van Wilgen, B.W., 2004. Invasive alien plants in South Africa: how well do we understand the ecological impacts? South African Journal of Science $100,45-52$.

Richardson, D.M., van Wilgen, B.W., Higgins, S.I., Trinder-Smith, T.H., Cowling, R.M., McKell, D.H., 1996. Current and future threats to biodiversity on the Cape Peninsula. Biodiversity and Conservation 5, 607-647.

Richardson, D.M., Moran, V.C., Le Maitre, D.C., Rouget, M., Foxcroft, L.C., 2004. Recent developments in the science and management of invasive alien plants: connecting the dots of research knowledge, and linking disciplinary boxes. South African Journal of Science 100, 126-128.

Robertson, M.P., Peter, C.I., Villet, M.H., Ripley, B.S., 2003. Comparing models for predicting species' potential distributions: a case study using correlative and mechanistic predictive modelling techniques. Ecological Modelling 164, 153167.

Rouget, M., Richardson, D.M., Cowling, R.M., 2003. The current configuration of protected areas in the Cape Floristic Region, South Africa - reservation bias and representation of biodiversity patterns and processes. Biological Conservation $112,129-145$

Saaty, T.L., 1980. The Analytic Hierarchy Process: Planning, Priority Setting, Resource Allocation. McGraw-Hill, New York

Svarstad, H., Petersen, L.K., Rothman, D., Siepel, H., Watzold, F., 2008. Discursive biases of the environmental research framework DPSIR. Land Use Policy 25, $116-125$.

Vaidya, O.S., Kumar, S., 2006. Analytic hierarchy process: an overview of applications. European Journal of Operational Research 169, 1-29.

Valente, R.D.A., Vettorazzi, C.A., 2008. Definition of priority areas for forest conservation through the ordered weighted averaging method. Forest Ecology and Management 256, 1408-1417.

van Wilgen, B.W., Richardson, D.M., Seydack, A.H.W., 1994. Managing fynbos for biodiversity: constraints and options in a fire-prone environment. South African Journal of Science 90, 322-329.

van Wilgen, B.W., Nel, J.L., Rouget, M., 2007. Invasive alien plants and South African rivers: a proposed approach to the prioritization of control operations. Freshwater Biology 52, 711-723. 
van Wilgen, B.W., Le Maitre, D.C., Forsyth, G.G., 2008. The prioritization of species and primary catchments for the purposes of guiding invasive alien plant control operations in the terrestrial biomes of South Africa. Unpublished report. CSIR Natural Resources and the Environment, Stellenbosch.
Wadsworth, R.A., Collingham, Y.C., Willis, S.G., Huntley, B., Hulme, P.E., 2000 Simulating the spread and management of alien riparian weeds: are they out of control? Journal of Applied Ecology 37, 28-38.

Wiens, J.A., 1989. Spatial scaling in ecology. Functional Ecology 3, 385-397. 